\title{
BMJ Open Qualitative study of telemonitoring of blood glucose and blood pressure in type 2 diabetes
}

Janet Hanley, ${ }^{1,2}$ Peter Fairbrother, ${ }^{3}$ Lucy McCloughan, ${ }^{4}$ Claudia Pagliari, ${ }^{4}$ Mary Paterson, ${ }^{4}$ Hilary Pinnock, ${ }^{4}$ Aziz Sheikh, ${ }^{4}$ Sarah Wild, ${ }^{4,5}$ Brian McKinstry ${ }^{2,4}$

To cite: Hanley J,

Fairbrother P, McCloughan L, et al. Qualitative study of telemonitoring of blood glucose and blood pressure in type 2 diabetes. BMJ Open 2015;5:e008896.

doi:10.1136/bmjopen-2015008896

\section{- Prepublication history and additional material is available. To view please visit the journal (http://dx.doi.org/ 10.1136/bmjopen-2015- 008896).}

Received 25 May 2015 Revised 28 September 2015 Accepted 5 October 2015

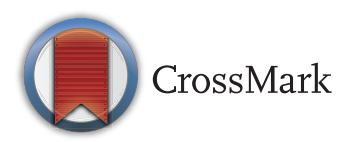

\footnotetext{
${ }^{1}$ Department of Nursing Midwifer and Social Care, Edinburgh Napier University, Edinburgh, UK

${ }^{2}$ Edinburgh Health Services Research Unit, Edinburgh, UK ${ }^{3}$ Department of Public Health, NHS Lothian, Edinburgh, UK

${ }^{4}$ Usher Institute of Population Health Sciences and Informatics, University of Edinburgh, Edinburgh, UK ${ }^{5}$ Department of Public Health Sciences, University of Edinburgh, Edinburgh, UK
}

Correspondence to Dr Janet Hanley; j.hanley@napier.ac.uk

\section{ABSTRACT}

Objectives: To explore the experiences of patients and professionals taking part in a randomised controlled trial (RCT) of blood glucose, blood pressure (BP) and weight telemonitoring in type 2 diabetes supported by primary care, and identify factors facilitating or hindering the effectiveness of the intervention and those likely to influence its potential translation to routine practice.

Design: Qualitative study adopting an interpretive descriptive approach.

Participants: 23 patients, 6 nurses and 4 doctors who were participating in a RCT of blood glucose and BP telemonitoring. A maximum variation sample of patients from within the trial based on age, sex and deprivation status of the practice was sought.

Setting: 12 primary care practices in Scotland and England.

Method: Data were collected via recorded semistructured interviews. Analysis was inductive with themes presented within an overarching thematic framework. Multiple strategies were employed to ensure that the analysis was credible and trustworthy.

Results: Telemonitoring of blood glucose, BP and weight by people with type 2 diabetes was feasible. The data generated by telemonitoring supported selfcare decisions and medical treatment decisions. Motivation to self-manage diet was increased by telemonitoring of blood glucose, and the 'benign policing' aspect of telemonitoring was considered by patients to be important. The convenience of home monitoring was very acceptable to patients although professionals had some concerns about telemonitoring increasing workload and costs.

Conclusions: Telemonitoring of blood glucose, BP and weight in primary care is a promising way of improving diabetes management which would be highly acceptable to the type of patients who volunteered for this study.

Trial registration number: ISRCTN71674628; Pre-results.

\section{BACKGROUND}

As the population ages, more people live with long-term conditions, particularly type 2

\section{Strengths and limitations of this study}

- Trial context led to wide range of practices participating.

- Telemonitoring was provided within the practice by the .patients' usual clinicians.

- Small numbers telemonitoring in each practice.

- The practices involved had low non-Caucasian ethnic minority populations who are at higher risk of type 2 diabetes.

diabetes. The WHO estimates that globally $8-10 \%$ of adults over the age of 25 have diabetes, approximately $90 \%$ with type 2 diabetes. ${ }^{1}$ Close control of blood glucose and blood pressure (BP) can reduce morbidity. ${ }^{2-4}$ As the prevalence of chronic conditions such as type 2 diabetes increases, it will become difficult to continue to provide the same level of healthcare staffing to manage these conditions as we do now. Many healthcare strategy documents advocate the use of telehealth (particularly telemonitoring and teleconsultation $)^{5}$ to streamline and improve the management of long-term conditions and produce engaged $^{6}$ and activated ${ }^{7}$ patients who manage their own condition well, requiring fewer consultations and fewer admissions to hospital. However, despite numerous pilot studies, the uptake of telehealth has been limited and in the UK and some healthcare providers are now disinvesting in telemonitoring technologies for a range of reasons ${ }^{8}$ including negative results from some trials, and the cost and difficulty in sourcing systems which meet their needs. ${ }^{9} 10$ Telemonitoring, where the patient regularly measures signs and symptoms at home and makes them electronically available to their healthcare provider, is a complex intervention, requiring input from patients and providers. Analysis of the reasons for effectiveness or otherwise of complex interventions is best addressed using qualitative methods. ${ }^{11}$ This paper presents 
the results of a qualitative study of telemonitoring in type 2 diabetes in the context of the effective Telescot Diabetes randomised controlled trial (RCT) which will be reported elsewhere (Trial registration number ISRCTN71674628). ${ }^{12}$

Good blood glucose control and good BP control $(<130 / 80 \mathrm{~mm} \mathrm{Hg})$ can substantially reduce the risk of cardiovascular complications in people with type 2 diabetes. ${ }^{13}$ However, evidence of the value of selfmonitoring blood glucose for those who are not on insulin is mixed. ${ }^{14}$ It is not routinely recommended in the UK, ${ }^{13}{ }^{14}$ due to cost concerns and research suggesting that it does not improve control and may increase anxiety. ${ }^{15}$ Syntheses of qualitative studies ${ }^{16}{ }^{17}$ report that self blood glucose monitoring has a perceived negative impact on quality of life where the monitoring identifies problems which are not addressed, for example, when patients were aware of high readings for long periods in between clinic appointments. ${ }^{18}$ In contrast, telemonitoring provides timely sharing of clinical information with healthcare providers and the limited evidence available suggests it helps improve blood glucose control in type 2 diabetes, ${ }^{19}$ although the authors of a recent analysis of data from a large cluster RCT in England suggest that the improvement in blood glucose control may not be large enough to be clinically significant. ${ }^{20}$ The evidence for telemonitoring $\mathrm{BP}$ is growing, ${ }^{21-26}$ but the acceptability and impact of this in people with type 2 diabetes who are also being asked to monitor their blood glucose is unclear.

The Telescot programme consisted of a series of randomised controlled trials with embedded qualitative studies in telemonitoring in chronic obstructive pulmonary disease (COPD), hypertension and diabetes, with additional pilot and qualitative studies of telemonitoring in heart failure and hypertension following stroke. The defining feature of this programme was that, unlike in many previous pilots/trials, telemonitoring was provided by the patients' usual primary care practitioners so that apart from the telemonitoring, the same care was available to control and intervention groups. This approach was shown to be effective in improving the management of BP in people who did not have diabetes. In the trial which was the context for this qualitative study people with type 2 diabetes were asked to telemonitor three risk factors, blood glucose, BP and weight over a period of 9 months. This added complexity to telemonitoring for patients and practitioners, necessitating this qualitative study to examine process and reasons for the effectiveness or otherwise of this complex intervention. All patients had poor blood glucose control at the start of the study, but not necessarily poor BP control. ${ }^{12}$

A number of qualitative studies from this programme have already been published ${ }^{27-33}$ and strong themes are emerging. Broadly, the previous studies indicated that telemonitoring is welcomed by patients who find it convenient, ${ }^{27} 31$ appreciate being "watched over,28 29 and find the data reassuring. ${ }^{27} 2932$ Some found it empowered them to use the healthcare system more efficiently and effectively. ${ }^{27}{ }^{29}$ However, although healthcare practitioners recognised the potential patient benefits, they were concerned that some patients may become dependent on the technology and anxious about their condition, ${ }^{27-30}{ }^{32}$ that responding to telemonitoring data did not fit with their customary ways of working ${ }^{27} 33$ and that it increased consultation rates. ${ }^{27} 29$ There was a difference in response to the parameters being monitored, with home BP measures providing a trusted basis for treatment modification and thus an improvement on surgery measurement ${ }^{27}$ compared with COPD, where the parameters measured (symptom scores, pulse oximetry and forced expiratory volume in $1 \mathrm{~s}$ ) did not provide a reliable basis for treatment decisions without further investigation. ${ }^{28} 2932$

\section{METHODS}

\section{Overview}

This study was embedded within a multicentre RCT of blood glucose, BP and weight telemonitoring in routine care for patients whose glycated haemoglobin (HbAlc) was above the target range (box 1). ${ }^{12}$ Qualitative data were collected via semistructured interviews with participating patients and professionals. An interpretive descriptive approach $^{34}$ was employed, acknowledging that in health services research the need of the researcher is not simply to provide a description of the phenomenon, but also to produce an interpretive account which will help to guide healthcare innovation while, at the same time, recognising the subjective nature of the encounter between the participant and the researcher. ${ }^{35}$ Although there is evidence from our own and others' research, that patients' and professionals' perceptions and experiences of telemonitoring may differ ${ }^{27-32} 3637$ both perspectives need to be considered together in the context of an interpretive descriptive approach to a service delivered in partnership, and are necessary to inform a rounded interpretation of the data in this study. ${ }^{38}$

\section{Box 1 Telemonitoring intervention}

Participants in the telemonitoring group were given instructions for use of blood pressure (BP), blood glucose and weight monitors which used Bluetooth technology to transmit readings via a supplied modem to a remote secure server. The participant and their primary care professionals were able to access passwordprotected records on the server. Participants were asked to measure one fasting and one non-fasting blood glucose at least twice weekly and measure BP and weight at least weekly (with increased testing as recommended by the clinician for people treated with insulin). They were given advice on lifestyle modification, on lag time for effects of lifestyle and medication change on glucose and BP, and when and how to contact their healthcare advisor. Primary care nurses were asked to check participants results weekly and to organise treatment changes based on national guidelines for diabetes and hypertension management. For full details please see the published protocol. ${ }^{12}$ 


\section{Ethics and governance considerations}

The trial ${ }^{12}$ took place in general practitioner (GP) practices in three Health Board areas in Scotland (Lothian, Borders, Greater Glasgow and Clyde) and one county in England (Kent). The study received ethical approval from the South East Scotland Ethics Service (10/S1102/ 60) and R\&D approvals from the Scottish Health Boards and the Research Management and Governance (RM\&G) Consortium for Kent and Medway. This qualitative study took place in Lothian and Kent. Patients were made aware that they may be approached for the embedded qualitative study when they agreed to participate in the trial, but that participation in the qualitative study would be optional. Patients and professionals approached were sent a separate information sheet about the qualitative study and gave additional written consent prior to participation.

\section{Sampling and recruitment}

Forty-two GP practices and 321 patients participated in the RCT. A maximum variation patient sample of at least 20 patients from the intervention arm from 12 of these practices in Lothian and Kent (where the majority of participating practices were located) was sought based on age, sex and the deprivation status of the practice. Patients participating in the trial were purposively sampled and checks were made with the practice to ensure that it was still appropriate to approach the patient before they were contacted by letter. Those who did not respond were replaced by patients taking part in the trial with similar characteristics. The aim of this sampling strategy was to capture a broad range of participant experiences across the socioeconomic spectrum. Interviews were also sought with at least one professional from each practice.

\section{Data generation}

Qualitative data were gathered through semistructured interviews with patients, nurses and doctors. Initial topic guides were based on issues identified in previous telemonitoring studies and were refined iteratively in response to the initial interviews. The final topic guides are shown in online supplementary appendix 1 . Some participants from Lothian were interviewed face-to-face in their own home, and professionals at their workplace, with all other interviews carried out by telephone. Interviews were carried out by $\mathrm{PF}$, a male qualitative researcher who was not involved in the RCT.

\section{Data handling and analysis}

Data were collected between July 2011 and March 2012 and, with a little variation due to availability, in tranches reflecting different start dates of the trial in different practices. Provisional coding and identification of themes took place after each tranche of interviews. Interviewing continued until the researcher, in discussion with the wider research team, considered that data saturation had been achieved. Although there is discussion on the concept of data saturation, ${ }^{39}$ in the context of this study it was considered to have occurred when the researcher was not identifying any new themes or codes within the provisional themes in sequential interviews and thought this would be unlikely in subsequent interviews.

All interviews were recorded, fully transcribed and the transcript checked against the recording. They were analysed thematically with initial codes and themes identified inductively from the data. Patient and professional data were initially coded separately and coding was recorded using Nvivo V.7. Initial codes from patients and professionals were grouped into themes and a framework of overarching themes developed, in line with the interpretive descriptive approach, with reference to the purpose of this study. A range of strategies was employed to ensure that the analysis was credible and trustworthy. Constant comparison was used to ensure consistency in coding and negative cases were sought for each coding category. Coding was checked and iteratively refined using paired analysis of transcripts by two researchers (PF and JH). Researcher reflexivity was supported by discussing emerging findings at regular meetings with the wider research group where different explanations were explored and the coding and thematic analysis reviewed and refined. In July 2012, the thematic analysis was presented by $\mathrm{PF}$ to a discussion group of researchers who had participated in the Telescot programme. The presentation introduced the themes and illustrative quotes and the whole data set (all the text associated with each code) was made available to the participants.

\section{RESULTS}

Thirty-six patient participants were approached and 23 interviewed, 16 men and 7 women, mean age 60 years. Seven were interviewed face-to-face, the remainder by telephone. Fourteen professionals were approached and 10 interviewed, 4 GPs and 6 practice nurses. Eight were interviewed by telephone, two face-to-face.

\section{Overview}

The results are presented in the context of a broad overarching framework of factors which influence outcomes and potential adoption of telemonitoring of type 2 diabetes in primary care including contextual factors, communication (including performance of the technology), telemonitoring as support for managing the condition, and 'fit' of telemonitoring with personal lifestyles and professional practice in primary care. The coding frame used in this study is available in online supplementary appendix 2. In the illustrative quotes presented below, practitioners are identified only by profession to reduce the possibility of recognition.

\section{Contextual factors}

Patients and professionals spoke about a number of aspects of the context into which telemonitoring was 
introduced which were likely to influence its impact. They included patients' prior experience of living with type 2 diabetes, the nature of usual care, preferred methods of managing diabetes and the context of the clinical trial.

\section{Living with type 2 diabetes}

No patients in this study had newly diagnosed type 2 diabetes so all had experience of living with the condition. Several patients described the expectation that they constantly needed to self-manage their diabetes and the wearisome nature of this.

I've been diabetic for quite a few years now and it's quite wearing and I go through phases where you just lose interest, you know, and I'm told that's quite normal.

(Patient 6, Male, 50-54 years, Kent)

Patients said less about their BP and appeared to be less well informed about it

Interviewer: ...when you've had your blood pressure taken at the surgery, do they tell you the number?

Patient: Yes.

Interviewer: And is that actually helpful to know?

Patient: No. Because I've no idea what it should be... so I've been on the net, checking what it should be.

(Patient 12, female, 60-64 years, Lothian.

\section{Usual care}

The frequency with which patients with type 2 diabetes were seen in primary care prior to this trial varied. Nurses pointed out that to some extent this was dependent on the patients' level of control (although all patients in the trial had poor levels of diabetic control recorded prior to recruitment) and different treatment methods, with insulin treated patients requiring greater supervision. However, there also appeared to be variation between practitioners

... every year with this new nurse ..., but the one before her used to take me in every four months and check me out.

(Patient 1, male, 60-64 years, Lothian)

At the start of the trial three patients were already monitoring their blood glucose and sharing the results manually with their doctors or nurses at their regular appointments. However, at least one of the nurses felt that the value of this was limited for those patients who did not share 'bad' readings.

if patients seem to have got really bad results, they tend to forget their book! Or they're not recording it anyway

(Practice nurse 10).

\section{Preferred management options}

Minimising medical intervention and managing diabetes using lifestyle measures was clearly the first choice of approach.

She wants to put me on this glycoside tablet to enhance whatever I've got in my body. I'm fighting against it. I says, I'll try and get my weight down. When my weight goes down, everything goes down, blood sugars and the blood pressure goes down

(Patient 13, male, 60-64 years, Lothian)

The diabetic nurse has picked up the phone twice to call me, looking at the results and to discuss a couple of things, so that was quite useful... It's actually led to a radical change in diet, following a discussion she had with our specialist diabetic GP

(Patient 6, male, 50-54 years, Kent)

However, for BP control, changes to medication initiated by professionals were mentioned more frequently.

Yes, my diabetic practitioner nurse does call me about the readings, in fact she has modified my blood pressure control medication a couple of times to bring the levels down to a more acceptable level, so yeah, it's been a definite benefit I think

(Patient 7, male, 55-59 years, Kent).

\section{Trialling}

The final major contextual factor was the trial itself. Both patients and professionals appreciated being able to try the systems without committing to using them on a longterm basis, as well as the opportunity to contribute to healthcare research. Thus, although all of the participants were volunteers, the sample may have included people who would not have agreed to use the system had it been a long-term or (for professionals) full scale commitment.

\section{Communication}

The telemonitoring system was a vital aspect of communication and most people reported minor technical problems with the system at some point (mainly stemming from one particular firmware update), but many people were happy to continue to use it as part of a trial to help determine the possibilities of telemonitoring. However system failures were enough to put some patients off continuing with telemonitoring.

but the second patient dropped out of the trial because he moved house, but also he was having quite a lot of problems with the equipment. I think [IT support] had phoned me a couple of times because the Bluetooth wasn't working and I think he did get a bit disheartened with it

(Practice nurse 9) 
Although patients could see their record on the internet and there was a level of automated feedback from the system, the system itself did not provide a simple way of communicating asynchronously between patients and professionals. In particular, patients were unable to tell whether their readings had been viewed.

I think it's quite good to put the information through. As I say, Dr. [name] has only been in touch once, so whether he's actually looking at the thing I don't know, who can tell

\section{(Patient 10, female, 70-74 years, Lothian)}

So I don't know whether the doctor must be looking at it, or the nurse is maybe looking at it and no switched it off

(Patient 4, female, 50-54 years, Lothian)

There was uncertainty about who should be responsible for initiating communication if readings were outside the target range. Some patients would wait for the practice nurse to contact them, which many did, others would initiate the communication themselves.

But I don't know what to do if...I think that if it goes above 15, you have to do it again or something like that... I would let my practice get in touch with me, because I'm not very sure of what it all means.

(Patient 20, male, 55-59 years Lothian)

Well, I like to keep a weather eye on things. As for instance, I noticed that my blood pressure was not very high, but was in the high zone, and I brought that to their attention and said I was concerned, you know, that it should be lower. And as a consequence, they changed the medication, and it is now within the realms of being nearly normal now

(Patient 8, female, 50-54 years, Kent).

\section{Telemonitoring as support for managing the condition}

Telemonitoring data supported the management of the condition in two ways-supporting self-care by the patient and supporting treatment changes by the primary care team/GP.

\section{Supporting self-care}

The use of the telemonitoring data to support self-care was a strong theme. The response to high blood sugar readings was immediate for some people.

but as far as I'm concerned the minute I see my blood sugar high, I definitely don't eat anything. I make sure to try and bring it down.

(Patient 22, Male 50-54 years, Lothian)

it's a good way of keeping track, on how you're progressing, and rather than going to the health centre every three months, or four months, whatever, and then found that you're slipping a bit, or your readings are going out of control again,.

(Patient 10, male, 55-59 years, Kent)

The behavioural impacts indicated by the quotations above could be attributable to the insights generated by access to self-monitoring data, however the responses of some participants also suggested that believing their readings may be observed by their health providers is what motivated them to act.

it's also a deterrent because I like a drink unfortunately .... It's sneaky beaky, it's good sneaky beaky.

\section{(Patient 14, Male, 50-55 years, Lothian)}

But knowing that everything's going to be looked at on a regular basis by somebody else, it's actually, it's not bad to have a policeman somewhere ....

(Patient 6, male, 50-55 years, Kent)

Practitioners thought the system would be particularly useful for those using insulin.

I think the patients who this is probably helpful for are those on the insulin, because they're the ones who will be adjusting their insulin dose according to what their blood sugars are.

(Practice nurse 2).

\section{Supporting treatment changes}

The second use of the telemonitoring data was as a basis to change medical treatment. Frequent testing led to faster working through treatment protocols in some cases. However, as shown in the second example, not all professionals were willing to engage with the home monitoring data.

I've got another gentleman that probably he needs to go on insulin. And we've, sort of, been watching whilst we've given him some tablets and they really haven't made any difference. So his treatment is going to change quicker than it would have done, sort of, normally.

\section{(Practice nurse 3)}

... from our point of view it's not really going to change what we'll do, I mean I'll change the medication based on her next HbAlc result rather than anything else .... it's potentially harmful to her to expect that blood glucose monitoring with home strips is actually useful when in reality we are just going to be keeping on checking her HbAlc ... but I mean who knows whether it's stimulated her thoughts and feelings about her diabetes and made her focus more on her diet and things

(GP11) 
Some of these treatment changes were made without the need for the patient to visit the practice.

I got a letter to say that it $[\mathrm{BP}]$ was a wee bit high, and I was to go and see a doctor, and he said, 'Well come back in four weeks' time,' but ...I didn't put on an appointment, because I was going away on holiday ... So, by the time I come back there was a letter there, and they'd changed my medication.

(Patient 20, male, 55-59 years, Lothian)

\section{The 'fit' of telemonitoring with personal lifestyles and professional practice}

Within this theme there were major differences between patients and professionals. For patients telemonitoring was not a burden, it was convenient and made sense. Patients also thought that in the longer term it would reduce the burden on the practice by reducing the number of appointments required.

I think that's beneficial to both the diabetes nurse, because she can pick up the records from a distance,... and also it stops me having to physically go so often to the doctors' surgery, and I would have thought it would save a lot of time on the nursing/doctor side.

(Patient 7, male, 50-55 years, Kent)

I thought it was very useful because I was working at that time and I thought that the doctor was going to know everything about my illness and I don't really need to go and see the doctor.

(Patient 14, male, 50-55 years, Lothian)

However, although some professionals shared the patients' view that telemonitoring would be beneficial to the practice, others were concerned about workload and cost as shown in these contrasting examples.

I see it having a good impact on the practice, I don't see it being a negative impact. I think long term, if the patients are able to see what their readings are in the house and keeping an eye on their weight and looking after their blood pressure...... inevitably they will have better controlled diabetes ..... The time will free up for us.

\section{(Practice nurse 1)}

I think it's difficult when you're constrained by the pharmaceutical budget, you know, to say to somebody 'No you can't have a monitor' because that's basically what we're being told, you know, the prescribing of the blood glucose monitoring strips are expensive, and we shouldn't routinely be doing this.

(Practice nurse 9)
I mean it's easy enough to have monitors in various patients' houses generating numbers that may or may not be concerning ..... generating work potentially which we probably don't have the capacity to take on.

\section{(GP 11)}

The professionals were used to a model of care where communication with the patient was largely face to face and many continued with that model even when, from the patient's point of view, it was not needed or efficient.

...the receptionist rang up one morning and said, oh, Doctor [name] wants to see you about your blood test. ... when I got up there, he just said oh yeah, he'd got them from last week and they were alright, so I don't know what the panic... was all about.

(Patient 11, female, 70-74 years, Lothian)

.....this is all good technology but it's important to review your patients in person and place everything in context.

(GP 4)

However, as seen above and in this additional example, some GPs were willing to adjust BP medication remotely which was very acceptable to patients.

A couple of times they phoned me telling me that my blood pressure was too high and telling me that they'd be sending me a new prescription through the post which they did. I thought that was bloody wonderful.

(Patient 14, male, 50-54 years, Lothian).

\section{DISCUSSION}

The findings from this study suggest that telemonitoring of blood glucose and BP by people with type 2 diabetes was feasible. The data generated by telemonitoring supported self-care decisions and medical treatment decisions. In terms of self-care, the motivation to manage diet (the preferred method of improving diabetic control) was not just due to the patient seeing high blood glucose measurements, but also because the measurements may be seen within the practice, and patients considered the benign policing aspect of telemonitoring to be important. A similar finding was reported in a recently published study from New Zealand. ${ }^{40}$ The convenience of telemonitoring was very acceptable to patients although professionals had some concerns about telemonitoring increasing workload and costs. The findings indicated that there was a lack of consensus on who (patient or practitioner) should initiate communication if readings were outwith the target range and the mode of communication, with telephone and letter being used but some practitioners preferring to see patients face to face. 
A strength of this study is that it was embedded in an RCT, (the results of which will be published elsewhere). Qualitative studies nested within clinical trials of complex interventions can identify how the intervention was applied and the mechanism by which it induces change ${ }^{41}$ particularly useful in trials such as this where guidelines rather than a strict protocol for the use of the telehealth intervention within the practices were issued. ${ }^{12}$ The results can be used to improve future guidance and iterations of the technology. Also professionals in particular welcomed the chance to test the new technology with no commitment to continue, and it may have been used by practices who would not otherwise have been 'early adopters'. According to the diffusion of innovations theory,${ }^{42}$ the trialability of an innovation is one of the properties which affects the chances of it being adopted, and in the trial context the technology was easy for practices to try on a small scale.

However, the trial context is also a weakness of the study, since the lack of full scale commitment to telemonitoring within a practice means that professionals did not experience providing the service at the scale required should it be adopted as routine care, and it is clear that large numbers of successful telehealth pilots have failed to translate into routine service. ${ }^{8}$ In addition participants in RCTs are often not representative of the wider population of people with diabetes. The participation rate in the Telescot diabetes trial was only $12 \%$ and there was over representation of men and younger people and under-representation of more socioeconomically deprived populations compared to the distributions among people with diabetes in the general population (S Wild, The impact of supported telemetric monitoring in people with type 2 diabetes, personal communication). Also Lothian and Kent have non-Caucasian ethnic minority populations of only $4 \%$ and $5 \%$, respectively ${ }^{43} 44$ and, although the ethnic mix of participants in the trial and this qualitative study was representative of the local populations, this study could not provide insight into the acceptability of telemonitoring for these groups who are at higher risk of type 2 diabetes.

The results of the Telescot programme of qualitative studies of telemonitoring ${ }^{27-33}$ show a number of common themes. Where this study differed is in the strong self-management response. Type 2 diabetes is the only condition which patients said that they expected to self-manage on a day-to-day basis even though over the long term it was difficult to maintain motivation. As well as supporting self-care, the telemonitoring data supported optimisation of treatment, particularly in relation to BP. Patients found telemonitoring a convenient way to communicate with healthcare professionals. However, some professional responses were more wary and suggest a lack of 'fit' between telemonitoring and current expectations of professional practice which may limit translation into routine practice. ${ }^{45}$ Other studies have suggested that much more attention needs to be paid to workflow within practices when designing telehealth systems which will be acceptable on a long-term basis. ${ }^{33}$ Despite this, there was evidence that some professionals were willing to change BP medication without seeing the patient face to face, although for others that remained the only mode of communication.

\section{CONCLUSIONS}

Telemonitoring in type 2 diabetes was well accepted by trial participants and increased motivation to improve self-management. It also provided clinicians with a quantitative basis on which to improve the medical management of BP. Some professionals harboured concerns about the potential for the service to increase workload and cost and some expressed a reluctance to move away from traditional exclusive face to face care, but this was not universal. There is need for further refinement of telehealthcare delivery models and technical improvements in telemonitoring systems, as well as wider cultural change on the part of patients and clinicians. More evidence of the beneficial effects of these interventions on patients' self-care motivation and behaviour may help to encourage clinicians to adopt these technologies in routine practice.

Acknowledgements The authors thank the practices and patients who participated in the study. Practices were recruited by the Scottish Primary Care Research Network, PCRN South East and the Comprehensive Local Research Network for Kent and Medway. The study was overseen by the Telescot independent steering committee, Professor Sir Lewis Ritchie, Professor Ann-Louise Kinmonth and Professor Chris Griffiths.

Contributors JH, BM, SW, HP, AS and CP designed the study. SW led the clinical trial, $\mathrm{JH}$ led this qualitative study and BM led the overall programme. PF collected the data and led the analysis, LM and MP provided programme and trial management. All authors were involved in writing the paper.

Funding This study was funded by the Scottish Government Chief Scientist Office.

Patient consent Obtained.

Ethics approval SESREC.

Provenance and peer review Not commissioned; externally peer reviewed.

Data sharing statement No additional are data available.

\section{Competing interests None declared}

Open Access This is an Open Access article distributed in accordance with the Creative Commons Attribution Non Commercial (CC BY-NC 4.0) license, which permits others to distribute, remix, adapt, build upon this work noncommercially, and license their derivative works on different terms, provided the original work is properly cited and the use is non-commercial. See: http:// creativecommons.org/licenses/by-nc/4.0/

\section{REFERENCES}

1. World Health Organisation. Global status report on NCDs 2010 Geneva: WHO, 2011:15-16.

2. Holman RR, Paul SK, Bethel MA, et al. 10-year follow-up of intensive glucose control in type 2 diabetes. $N$ Engl $\mathrm{J}$ Med 2008;359:1577-89.

3. Holman RR, Paul SK, Bethel MA, et al. Long-term follow-up after tight control of blood pressure in type 2 diabetes. N Engl J Med 2008;359:1565-76.

4. Colhoun HM, Betteridge DJ, Durrington PN, et al. Primary prevention of cardiovascular disease with atorvastatin in type 2 diabetes in the 
Collaborative Atorvastatin Diabetes Study (CARDS): multicentre randomised placebo-controlled trial. Lancet 2004;364 (9435):685-96.

5. Department of Health. Building telecare in England. Department of Health, 2005:1-21.

6. Wanless D. Securing our future health: taking a long term view. A final report. London: HM Treasury, 2002.

7. Hibbard J, Gilburt H. Supporting people to manage their health. An introduction to patient activation. London: Kings Fund, 2014.

8. Chambers R. Tackling Telehealth: How CCGs can commission successful telehealth services. http://www.insidecommissioning.co. uk/article/1286743/ccgs-commission-successful-telehealth-services (accessed 4 May 2015).

9. Steventon A, Bardsley M, Billings J. Effect of telehealth on use of secondary care and mortality: findings from the Whole System Demonstrator cluster randomised trial. BMJ 2012;344: e3874.

10. Pinnock H, Hanley J, McCloughan L, et al. Effectiveness of telemonitoring integrated into existing clinical services on hospital admission for exacerbation of chronic obstructive pulmonary disease: researcher blind, multicentre, randomised controlled trial. BMJ 2013;347:f6070.

11. MRC. Developing and evaluating complex interventions: new guidance. http://www.mrc.ac.uk/documents/pdf/complexinterventions-guidance/ (accessed 8 May 2015).

12. Wild S, Hanley J, Lewis S, et al. The impact of supported telemetric monitoring in people with type 2 diabetes: study protocol for a randomised controlled trial. Trials 2013;14:198

13. Scottish Intercollegiate Guidelines Network. Clinical Guideline 116 Management of Diabetes. http://www.sign.ac.uk/guidelines/fulltext/ 116/index.html (accessed 8 May 2015).

14. National Institute for Health and Care Excellence. CG87: The management of Type 2 diabetes. http://www.nice.org.uk/guidance/ cg87 (accessed 8 May 2015).

15. Farmer A, Wade A, Goyder E, et al. Impact of self monitoring of blood glucose in the management of patients with non-insulin treated diabetes: open parallel group randomised trial. $B M J$ 2007;335:132.

16. Chen $\mathrm{CM}$, Chang Yeh $\mathrm{M}$. The experience of diabetics on self-monitoring of blood glucose: a qualitative metasynthesis. $J$ Clin Nurs 2014;24:614-16.

17. Frost J, Garside R, Cooper C, et al. A qualitative synthesis of diabetes self-management strategies for long term medical outcomes and quality of life in the UK. BMC Health Serv Res 2014; 14:348

18. Peel E, Parry O, Douglas M, et al. Blood glucose self-monitoring in non-insulin-treated type 2 diabetes: a qualitative study of patients' perspectives. Br J Gen Pract 2004;54:183-8.

19. Polisena J, Tran K, Cimon K et al. Home telehealth for diabetes management: a systematic review and meta-analysis. Diabetes Obes Metab 2009;11:913-30.

20. Steventon A, Bardsley M, Doll $\mathrm{H}$, et al. Effect of telehealth on glycaemic control: analysis of patients with type 2 diabetes in the Whole Systems Demonstrator cluster randomised trial. BMC Health Serv Res 2014:14:334.

21. Agarwal R, Bills JE, Hecht TJW, et al. Role of home blood pressure monitoring in overcoming therapeutic inertia and improving hypertension control: a systematic review and meta-analysis. Hypertension 2011;57:29-38.

22. Bray EP, Holder R, Mant $\mathrm{J}$, et al. Does self-monitoring reduce blood pressure? Meta-analysis with meta-regression of randomized controlled trials. Ann Med 2010;42:371-86.

23. Verberk WJ, Kessels AG, Thien T. Telecare is a valuable tool for hypertension management, a systematic review and meta-analysis. Blood Press Monit 2011;16:149-55.

24. Omboni S, Guarda A. Impact of home blood pressure telemonitoring and blood pressure control: a meta-analysis of randomized controlled studies. Am J Hypertens 2011:24:989-98.
25. McManus RJ, Mant J, Bray EP, et al. Telemonitoring and self-management in the control of hypertension (TASMINH2) a randomised controlled trial. Lancet 2010;376:163-72.

26. McKinstry B, Hanley J, Wild S, et al. Telemonitoring based service redesign for the management of uncontrolled hypertension: multicentre randomised controlled trial. BMJ 2013;346:f3030.

27. Hanley J, Ure J, Pagliari C, et al. Experiences of patients and professionals participating in the HITS home blood pressure telemonitoring trial: a qualitative study. BMJ Open 2013;3:e002671.

28. Fairbrother P, Pinnock H, Hanley J, et al. Exploring telemonitoring and self-management by patients with chronic obstructive pulmonary disease: a qualitative study embedded in a randomized controlled trial. Patient Educ Couns 2013;93:403-10.

29. Ure J, Hanley J, Pinnock $\mathrm{H}$, et al. Piloting tele-monitoring in COPD: a qualitative exploration of issues in design and implementation for research and service development. Prim Care Respir $J$ 2012;21:57-64.

30. Fairbrother P, Ure J, Hanley J, et al. Telemonitoring for chronic heart failure: the views of patients and healthcare professionals-a qualitative study. J Clin Nurs 2014;23:132-44.

31. Hanley J, Fairbrother P, Krishan A, et al. Mixed methods feasibility study for a trial of blood pressure telemonitoring for people who have had stroke/transient ischaemic attack (TIA). Trials 2015;16:117.

32. Fairbrother P, Pinnock H, Hanley J, et al. Continuity, but at what cost? The impact of telemonitoring COPD on continuities of care: a qualitative study. Prim Care Respir J 2012;21:322-8.

33. Davidson E, Simpson C, Demiris G, et al. Integrating telehealth care-generated data with the family practice electronic medical record: qualitative exploration of the views of primary care staff. Interact J Med Res 2013;2:e29.

34. Sandelowski M. Whatever happened to qualitative description? Res Nurs Health 2000;23:334-40.

35. Thorne S, Kirkham SR, MacDonald-Emes J. Interpretive description: A non-categorical qualitative alternative for developing nursing knowledge. Res Nurs Health 1997;20:169-77.

36. McNeil V, Sanders C, Fitzpatrick R, et al. Experiences of front-line health professionals in the delivery of telehealth: a qualitative study. Br J Gen Pract 2014;64:e401-7.

37. Segar J, Rogers A, Salisbury C, et al. Roles and identities in transition: boundaries of work and inter-professional relationships at the interface between telehealth and primary care. Health Soc Care Community 2013;21:606-13.

38. Kendall M, Murray SA, Carduff E, et al. Use of multiperspective qualitative interviews to understand patients' and carers' beliefs, experiences, and needs. BMJ 2009;339:b4122.

39. Baker S, Edwards R. How many qualitative interviews is enough? ESRC National Centre for Research Methods review paper. http:// eprints.ncrm.ac.uk/2273/4/how many interviews.pdf (accessed 04 May 2015).

40. Kenealy TW, Parsons MJG, Rouse APB, et al. Telecare for diabetes, CHF or COPD: effect on quality of life, hospital use and costs. A randomised controlled trial and qualitative evaluation. PLOS ONE 2015;10:e0116188.

41. Lewin S, Glenton C, Oxman AD. Use of qualitative methods alongside randomised controlled trials of complex healthcare interventions: methodological study. BMJ 2009;339:b3496.

42. Rogers E. Diffusion of innovations. 5th edn. New York: Simon and Schuster, 2003. ISBN: 978-0-7432-5823-4.

43. http://www.gov.scot/Topics/People/Equality/Equalities/DataGrid/ Ethnicity/EthPopMig (accessed 27 Aug 2015).

44. http://www.kent.gov.uk/about-the-council/information-and-data/Factsand-figures-about-Kent/equality-and-diversity-data (accessed 27 Aug 2015).

45. May CR, Mair FS, Dowrick CF, et al. Process evaluation for complex interventions in primary care: understanding trials using the normalization process model. BMC Fam Pract 2007;8:42.

46. Koopman RJ, Wakefield BJ, Johanning JL, et al. Implementing home blood glucose and blood pressure telemonitoring in primary care practices for patients with diabetes: lessons learned. Telemed $J$ E Health 2014:253-60. 